\title{
An assessment of impact of income levels, family type, family size and food habit on the regularity of American food consumption in Bengaluru city
}

Pooja S. Bhat, T. N. Venkata Reddy and P. K. Mandanna

Received : 18.12.2017; Revised : 02.03.2018; Accepted : 16.03.2018

\begin{abstract}
There is an increase in the number of consumers dining from posh restaurants catering various cuisines and dishes to people across the world. The study targets to check if there is any impact of income level, family type, family size and food habiton the frequency of consumption of American foods in American Food Restaurants (AFR). Being an exploratory study, 90 consumers of American style foods in Bengaluru city were interviewed for which seven AFR's were carefully chosen and the data was analysed using Chi-square technique. From the findings, it is evident that there is impact of income level, family type and family size and no impact of food habit on the frequency of consumption of American foods in AFR's. The study concludes that profiling customers by their choice of preferences provides more meaningful ways to identify and understand various customer segments and marketing strategies.
\end{abstract}

KEY WORDS : American foods, Frequency, Impact, Lifestyle, Psychological factors

How to cite this paper : Bhat, Pooja S., Reddy, T.N. Venkata and Mandanna, P.K. (2018). An assessment of impact of income levels, family type, family size and food habit on the regularity of American food consumption in Bengaluru city. Internat. J. Com. \& Bus. Manage, 11(1) : 12-18, DOI: 10.15740/HAS/IJCBM/11.1/12-18. 